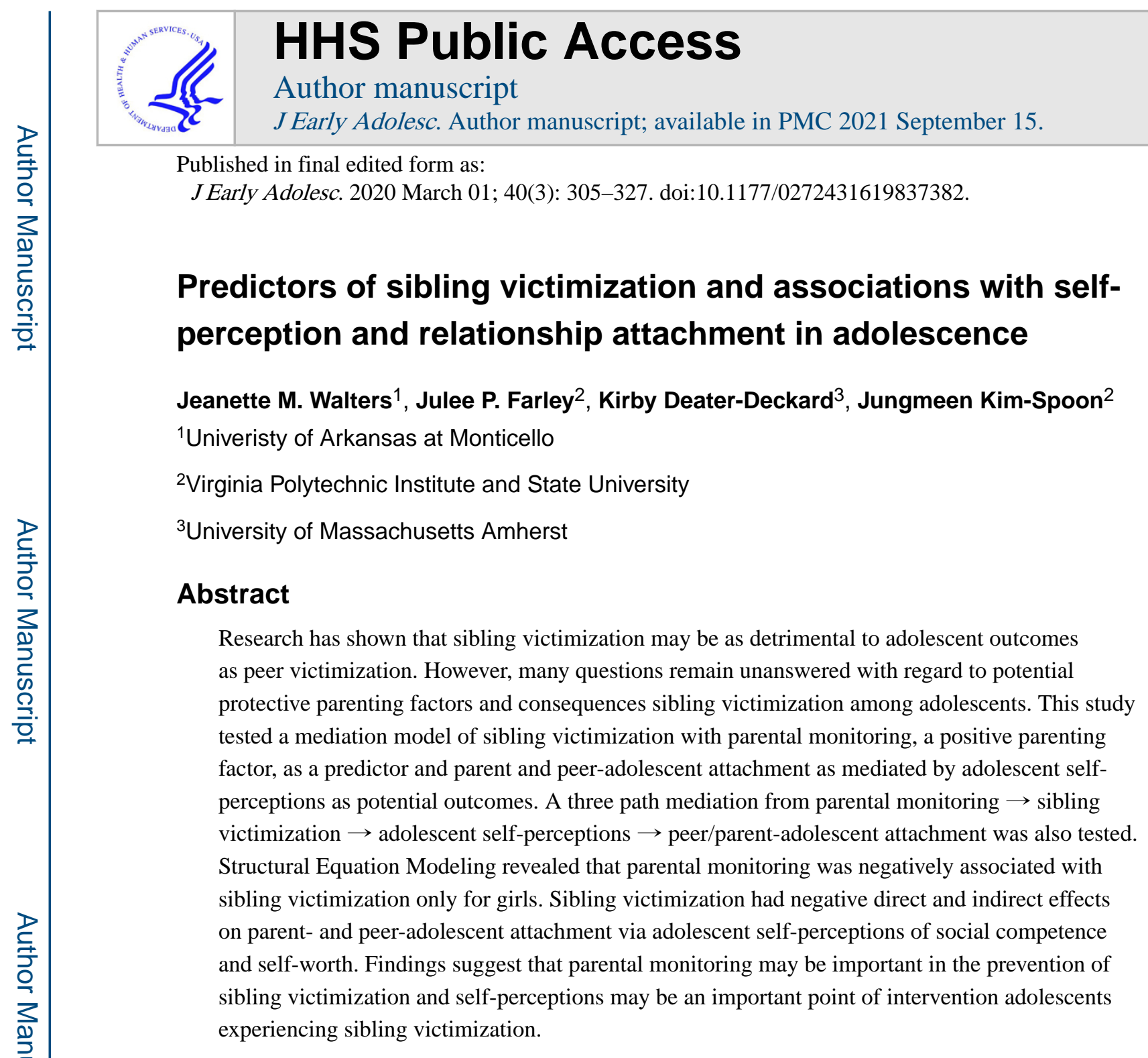

\title{
Keywords
}

sibling victimization; parental monitoring; adolescent self-perceptions; social competence; selfworth

Sibling victimization has been called the "most common but least researched form of family violence in the United States" (Krienert \& Walsh, 2011) and has been related to a number of detrimental outcomes in childhood including poor mental health (Tucker et al., 2013). Furthermore, research shows experience of sibling victimization may have long term consequences that last into adulthood such as substance use, aggression, depression, low self-esteem, and low sense of well-being (Morrill-Richards \& Leierer, 2010; Wiehe $\&$ Herring, 1991). Although awareness and literature on sibling victimization has been growing steadily, many questions still remain unanswered. The primary goal of this study was to address some of these questions in regards to parenting practices such as parental

Correspondence concerning this article should be addressed to Jeanette M. Walters, Department of Psychology, University of Arkansas at Monticello., waltersjm@uamont.edu. 
monitoring as a protective factor against sibling victimization and possible pathways by which parental monitoring and sibling victimization may be related to adolescent attachment with parents and peers. Specifically, we examined lack of parental monitoring as a predictor of occurrence of sibling victimization, and parental monitoring and sibling victimization as a predictor of peer- and parent-adolescent attachment. Additionally, given prior evidence that experience of maltreatment has effects on self-perceptions, that are in turn related to maladjustment (e.g., Boulton, Smith, \& Cowie, 2010; Kim \& Cicchetti, 2004), we examined adolescent self-perceptions of social competence and self-worth as possible pathways through which sibling victimization may be related to parent and peer attachment. An extended mediation model is proposed examining a three path mediation from parental monitoring to parent and peer attachment through sibling victimization and adolescence selfperceptions. Finally, given research evidence for gender differences in parental monitoring (Fagan et al., 2011), sibling victimization (Tucker, Finkelhor, and Turner, 2018), as well as other variables in the proposed model, potential gender differences were also examined.

In the following sections we offer research support and evidence for our hypothesized pathways. By using an extended mediation model, it is our intention to expand understanding of sibling victimization in context of parenting, specifically monitoring and also connections of both monitoring and sibling victimization to relationship attachment in adolescents.

\section{Sibling Conflict vs. Sibling Victimization}

Sibling victimization remains overlooked in many families as parents often label it as mere conflict or rivalry and consider it a normal part of sibling relationships (Kiselica \& Morrill-Richards, 2007). This attitude has caused a great deal of difficulty in attempting to define the difference between "normal" sibling conflict and sibling victimization; however, it is possible to distinguish between sibling conflict and sibling victimization and empirical evidence supports fundamental differences in outcomes among siblings who experience conflict versus victimization (Kiselica \& Morrill-Richards, 2007). Indeed, some degree of conflict may be considered a normal part of any relationship and research suggests that this is not always detrimental and may even have beneficial effects within relationships. Morrill-Richards and Leierer (2010) define conflict as "mutual disagreement over resources in the family". Under these circumstances, conflict among siblings can provide opportunities for growth and learning conflict resolution skills that can aid children in developing peer relationships (Herrera \& Dunn, 1997). Volling (2003) reported that siblings who experience a moderate amount of conflict in their sibling relationships report greater warmth and affection for each other. Volling (2003), however, makes it clear that an important distinction is that conflict must be void of aggression to be either benign or beneficial to development. Interactions characterized by aggression, and imbalance of power, specifically one sibling exercising aggression to dominate another, distinguishes victimization from normal conflict. Wolke, Tippett, and Dantchev (2015) argue that lack of consistency in terminology has hindered clarity of definitions and thus research in this area as a whole. Though abuse and victimization may be considered synonyms, they suggest using the term bullying which "is a form of aggression between siblings that involves direct or indirect intentional and persistent behaviors with an imbalance of power." Inconsistent or infrequent behaviors or 
singular acts of aggression are not considered bullying/victimizing. For the current study, we have chosen to use the term "victimization" mainly because sibling victimization among our sample is measured using the Juvenile Victimization Questionnaire and we wished to remain consistent it the terminology with the established measure.

Like peer victimization, sibling victimization may be psychological or physical in nature (Morrill-Richards \& Leierer, 2010) and is related to a variety of detrimental outcomes including internalizing and externalizing behaviors, and depression (Garcia et al., 2000; Kim et al., 2007; Milevsky \& Levitt, 2005;). Sibling victimization may even be related to risk of peer victimization (Tucker, et al., 2014; Yabko, Hokoda, \& Ulloa, 2008). Thus, extant literature provides clear evidence indicating that sibling conflict and sibling victimization are distinct in both characterization and consequence.

\section{Predictors of Sibling Victimization}

Kramer (2010) argues that parenting plays a major role in the development of positive sibling relationships. Specifically, parents can model appropriate social behaviors, prompt and coach complex behaviors like emotion regulation and behavioral control, as well as reinforce positive behaviors and interactions. Research supports this supposition showing that parenting factors, such as paternal and maternal warmth, have been related to sibling warmth and attachment (Stocker \& McHale, 1992; East, 2009). Updegraff and colleagues (2005) found that parental warmth and involvement was related to lower levels of sibling relational aggression. In contrast, parental negativity is highly associated with concurrent sibling negativity (Kim, Hetherington, \& Reiss, 1999) and negative parenting practices such as overt favoritism, severe physical punishment, and neglect are strongly correlated with high levels of both sibling conflict and victimization (Hoffman \& Edwards, 2004). Lack of supervision by parents is highly related to sibling victimization in children ages two to nine years of age (Tucker et al., 2014); however, it is unknown whether supervision or monitoring plays an important role in occurrence of sibling victimization in adolescence.

Kramer, Perozynski, and Chung (1999) did research differential reactions to parental intervention in older and younger sibling dyads and discovered that parental intervention in sibling conflict is more beneficial in younger sibling dyads than in older dyads which would seem to indicate that less involvement for adolescents is better. However, the act of monitoring may occur without direct intervention and simple monitoring of adolescents alone may serve as a protective factor given that children will often behave differently if they know their parents are consistently paying attention. Parental monitoring, in particular, has been linked to the prevention of problem behavior such as substance use and antisocial behavior as well as a number of positive outcomes including self-esteem and academic achievement (Laird, Pettit, Dodge, \& Bates, 2003). In relation to siblings, low maternal monitoring has been shown to lead to imbalance of status and power in sibling dyads (East $\&$ Khoo, 2005) and sibling conflict in general is connected with low parental monitoring (Furman \& Giberson, 1995). Thus we propose to further the literature in this area by examining whether low parental monitoring of adolescents is predictive of higher occurrence of sibling victimization. 


\section{Sibling Victimization and Parent and Peer Attachment}

The quality and nature of sibling relationships plays a large role in the development of other relationships, especially the nature and quality of future relationships (Herrera \& Dunn, 1997; Volling, 2003). In a retrospective study of sibling victimization and dating relationships, Simonelli and colleagues (2002) provided support for the idea that sibling victimization may have specific and detrimental effects on future relationships. The authors found that experience of sibling victimization in childhood was related to greater likelihood of both receiving and perpetrating violence (whether physical, emotional, or sexual) within a dating relationship. For males, the relationship of sibling victimization to dating violence was even stronger than the relationship of parental victimization to dating violence. Simonelli and colleagues (2002) concluded that experiencing sibling victimization may perpetuate a cycle of violence within relationships in a similar manner to experiencing parental victimization. Although extant research supports that sibling victimization may indeed affect dating relationship quality, the body of literature on the effects of sibling victimization on other types of relationships such as parent and peer relationships is still quite small, especially for adolescents. Bank, Burraston, and Snyder (2004) found that sibling conflict predicted later difficulties with peer relationships and antisocial behavior in adolescent boys. Research by Tippett and Wolke (2015) suggests that experience of sibling victimization increases the odds of peer victimization. Given that research has found support for the social learning theory perspective that sibling relationships may act as training grounds for peer relationships, it is plausible that experience of sibling victimization would be related to difficulty forming positive attachments in peer relationships.

Continuing with the logic that sibling victimization is related to quality of other relationships, we suggest that it might be an important predictor in parent-child relationships as well. Research has connected parental behaviors to occurrence of sibling victimization (Tucker et al., 2014) and parent-child relationship quality has been connected to sibling aggression (Updegraff et al, 2005), however, to date, research on the connection of parentchild relationships and sibling victimization has been unidirectional. We propose that the relationship may be bidirectional such that sibling victimization may be predictive of low attachment in the parent-child relationship. While peer relationships may be influenced by sibling victimization through social learning, the parent-child relationship may be influenced through lack of trust or feelings of not being valued by the parent leading to low attachment and poorer relationship quality overall. In sum, we propose that occurrence sibling victimization may be predictive of low peer and parent attachment. In the next section, we further explore this rationale by arguing for specific mechanisms by which sibling victimization may be related to parent/peer attachment.

\section{Sibling Victimization and Self-Perceptions}

Extant child maltreatment and peer victimization literature show that these factors have significant negative effects on children and adolescent's self-perceptions which are in turn related to negative outcomes. For example, in a longitudinal study of maltreated and non-maltreated school-aged children, Kim and Cicchetti (2004) found that maltreatment had significant negative effects on children's social competence, which in turn was 
negatively related to both internalizing and externalizing symptomatology. Research on peer victimization demonstrates that it also has significant negative effects on self-perceptions. Specifically, Grills and Ollendick (2002) found peer victimization to be negatively related to perception of self-worth in middle school children. Similarly, Boulton, Smith, and Cowie (2010) reported that experience of peer victimization in 9-10 year old children predicted negative changes in perceptions of social competence and self-worth five months later. Despite the connections in literature relating certain types of victimization to changes in self-perception, to the authors' knowledge, no research has examined sibling victimization in relation to self-perception. Thus, we propose to examine whether sibling victimization is related to low perceptions of self-worth and social competence. Furthermore, we propose that these self-perceptions may be pathways by which sibling victimization predicts peerand parent-adolescent attachment. Murray and colleagues (2000) found that low self-esteem was related to satisfying attachment in dating couples. Although this research was not done with adolescents, it provides precedence for examining a similar relationship during this developmental stage. As an example, sibling victimization may lower adolescents' perceptions of their own social competence and this lack of self-esteem in turn may lead to difficulty forming quality attachments to parents and peers. Similarly, sibling victimization may lower adolescents' perceptions of their own self-worth which may also hinder appropriate formation of attachments. Thus, in the current study, we examined whether self-perceptions of social competence and self-worth might be pathways by which sibling victimization may be related to peer- and parent-adolescent attachment.

\section{Gender Differences}

Extant research suggests that there may be gender differences with regard to the effects of negative interpersonal relationships on self-perceptions and adjustment outcomes. For example, peer victimization predicted changes in self-perceptions of social acceptance and self-worth for both boys and girls but predicted changes in perceptions of physical appearance and behavioral conduct only for girls (Boulton, Smith, \& Cowie, 2010). Peer victimization was negatively related to perception of self-worth for both boys and girls but that perception of self-worth mediated the association between peer victimization and anxiety only for girls (Grills \& Ollendick, 2002). These findings suggest that the relationship of victimization and self-perceptions may not function in the same way for both boys and girls. Furthermore, Kim and colleagues (1999) found that although negative/hostile sibling relationships had direct effects on externalizing behavior for both girls and boys, only for girls they also had an indirect effect on externalizing behavior through increased probability of involvement with deviant peers. The authors suggested that girls may be more reactive to conflict in sibling relationships. Tucker, Finkelhor, and Turner (2018) note that parents are more likely to monitor and dedicate supervision resources to girls than boys and that as a result, girls may be more vulnerable to sibling victimization. Thus, given evidence for gender differences in the effects of abusive and hostile relationships, we explored gender differences among the proposed relationships. 


\section{The Present Study}

The purpose of the current study was to examine a mediational model of predictors and consequences of sibling victimization. We examined whether parental monitoring would predict occurrence of sibling victimization and whether sibling victimization is associated with peer- and parent-adolescent attachment as mediated by adolescent selfperceptions of social competence and self-worth. We hypothesized that (1) low parental monitoring would be related to high occurrence of sibling victimization, (2) high occurrence of sibling victimization would be related to low peer- and parent-adolescent attachment, (3) the relationship of sibling victimization and peer- and parent-adolescent attachment would be mediated by self-perceptions of social competence and self-worth. We also hypothesized that a possible three path mediation of parental monitoring sibling victimization social competence and self-worth peer and parent-adolescent attachment might explain associations among these variables. Finally, the inclusion of examination of gender differences was largely exploratory but given that extant research shows that girls are more likely to be vulnerable to sibling victimization, and that girls may be more at risk for negative outcomes in victimization, we expect that the proposed pathways may be stronger for girls than for boys.

\section{Method}

Participants

Participants were part of a study conducting research on youth's healthy development and included 355 adolescents ( 165 girls) between the ages of 10 and 15 years $(M=13.03$, $S D=1.91$ ). Adolescents in the sample were $89 \%$ Caucasian with the other $11 \%$ reporting themselves as African-American, Hispanic, or other races. All adolescents had at least one sibling currently living in the household but further information on family size, age, or gender of the siblings was not collected. Primary caregivers (parents, hereafter; $\mathrm{N}=355$ ) also participated in the study. Parents were $81 \%$ mothers, $13 \%$ fathers, and 3\% other caregivers. Parent ages ranged from 25 to 69 years $(M=43.40, S D=6.95)$. Parents reported their race as $88 \%$ Caucasian with the remaining $12 \%$ reporting their race as African-American, Hispanic, or other races. Mean family income was between $\$ 35,000$ and $\$ 49,000$ a year.

\section{Procedures}

Participants were recruited from areas in a southeastern state via letters using address lists purchased from contact companies, email announcements, flyers, notices placed on the internet, or word-of-mouth. Adolescents and their parents were interviewed privately and simultaneously, and both received monetary compensation. Interviews were conducted by graduate students and research assistants in conference rooms in the university's psychology building. Interviews lasted on average 2 hours and participants were given several breaks throughout. The procedures of the current study were approved by the university's Internal Review Board. 
Demographic variables.-Demographic information of age, race $(0=$ White, $1=$ Ethnic/ Racial minority), parent's marital status (answers range from never married, divorced, separated, and married), and the annual household income $(1=$ None, $15=\$ 200,000+)$ was gathered from parents.

Parental monitoring.-Parents and adolescents were asked about parental monitoring habits using the 13-item Parental Knowledge subscale of the Child Monitoring Scale (CMS; Hetherington \& Clingempeel, 1992). This scale asks how much the parent knows about his/her adolescent's decisions about various aspects of the adolescent's life, such as performance in school, where the adolescent is when not at home, and dating behaviors. Answers on this scale range from " $1=$ Never knows" to " $5=$ Always knows". In the current sample, reliability was found to be .91 for adolescents' reports of mother's monitoring, .93 for adolescents' reports of father's monitoring, and .91 for parent's report of monitoring. Two adolescent participants reported on father's monitoring but not on mother's monitoring, whereas 22 adolescents reported on mother's monitoring but not on father's monitoring. A latent factor of parental monitoring was constructed based on adolescent reports of maternal and paternal monitoring and parent report of monitoring, described in Results below.

Sibling victimization.-Adolescents were asked to report on the Peer and Sibling Victimization module (six items) of the Juvenile Victimization Questionnaire (JVQ; Finkelhor, Hamby, Ormrod, \& Turner, 2005), which assesses victimization that has occurred in the past 12 months such as being hit, kicked/hit in the genitalia, picked on, and teased. A dichotomous 'sibling victimization' variable was created such that "1" indicated the adolescent endorsed that a sibling had done any of these actions to them, whereas " 0 " indicated otherwise. We also created a dichotomous 'other victimization' variable with " 1 " indicating victimization experiences by someone other than siblings and was used as a control variable for the occurrence of other possible forms of victimization in the adolescent's life. Previous research indicates that the JVQ is a reliable and valid measure of sibling and other victimization (Finkelhor et al., 2005).

Adolescent self-perceptions.-Adolescents were asked to respond to the 36-item Harter's Self-Perception Profile for children or adolescents (SPP: Harter, 1979). This questionnaire asks adolescents to choose one of two statements that is more like them (i.e., some kids are often unhappy with themselves BUT other kids are pretty pleased with themselves) and then endorse that statement as either "sort of true for them" or "really true for them". Answers are coded with values from one to four with higher values indicating better self-perceptions. The means of the social competence (six items) and global self-worth (six items) subscales were utilized in the present study because of their theoretical relationship to our outcomes of interest. In the current sample, reliability (coefficient $a$ ) for the social competence and global self-worth subscales for adolescents were .71 and .80 , respectively.

Parent and peer attachment.-Adolescents were asked to report on a shortened form of the Inventory of Parent and Peer Attachment (IPPA; Armsden, \& Greenberg, 1987; Raja, 
McGee, \& Stanton, 1992). These questionnaires asked about the level of perceived support from parents (12 items) and peers (12 items) separately. Answers for both scales ranges from " $1=$ Almost never or never true" to " $5=$ Almost always or always true" with higher values indicating higher levels of support. The mean of each scale was used in the present study. In the current sample, reliability was $a=.85$ and .82 for the parent and peer scales respectively.

\section{Results}

\section{Data Analysis Strategy}

We conducted Structural Equation Modeling (SEM) analyses using Mplus statistical software package (Muthén \& Muthén, 2010). The significance of mediation effects were tested using product-of-coefficients tests using the Delta method standard errors for twopath (single mediator) and three-path (two mediators in series) mediated effects (Taylor, MacKinnon, \& Tein, 2008). The two-path tests determined whether self-perception of social competence and self-worth were significant mediators in the relationship between sibling victimization and peer- and parent-adolescent attachment. The three-path mediation tests determined the significance of the effects of parental monitoring on peer- and parentadolescent attachment through sibling victimization and adolescent self-perception of social competence acceptance and self-worth. We examined how parental monitoring was related to sibling victimization and adolescent self-perception (both social competence acceptance and self-worth) as well as peer- and parent-adolescent attachment. We tested whether results differed for males and females using a two-group SEM with nested model testing where path coefficients were freed to vary or constrained to be equal for males and females. The significance of model fit differences was determined by Wald's Chi-square test.

\section{Preliminary Analyses}

Table 1 presents bivariate correlations among study variables as well as descriptive statistics. Multivariate general linear modeling (GLM) analysis of testing effects of demographic characteristics (including adolescent age, gender, race, and family income) revealed that adolescent age and family income had significant effects on parent attachment and peer attachment, respectively. Thus, adolescent age and family income were included as covariates in the main analyses. Additionally, victimization by individuals other than siblings was added as a covariate in order to examine the effects of sibling victimization over and above victimization by other individuals. Data were screened for outliers and multivariate non-normality using Mahalanobis's distance values. Eleven cases were shown to have a Mahalanobis's distance score greater than the critical value $\left[\chi^{2}(7)=24.322, p<\right.$ .001]. We compared models that included and excluded these cases and found highly similar model fit and path coefficients; thus, we included the cases in the main analyses. Skewness and kurtosis were also examined and fell within acceptable ranges (skewness less than 3 and kurtosis less than 10; Kline, 1998) with the exception of adolescent report of mother monitoring and parent report of monitoring. These variables were log transformed prior to main analyses. 


\section{Data Analysis}

We first conducted a confirmatory factor analysis to the test measurement structure of the latent factor of parental monitoring. The measurement model for the latent factor was a saturated model, $\chi^{2}=.00, d f=0, p=.00 ; \mathrm{CFI}=1.00$; RMSEA $=.00$. All factor loadings were significant and ranged from $r=.30-.87$. The main model (see Figure 1) examined effects of parental monitoring on peer- and parent-adolescent attachment as mediated through sibling victimization and adolescent self-perception of social competence and self-worth. Model fit was acceptable $\left(\chi^{2}=47.458, d f=14, p<.001\right.$; CFI = .93; RMSEA = .08). Parental monitoring $(b=-1.917, S E=1.496, p=.20)$ was not significantly related to sibling victimization. However, parental monitoring was positively related to perception of social competence ( $b=1.181, S E=.609, p=.049)$, perception of self-worth $(b$ $=3.721, S E=.529, p<.000)$, parent-adolescent attachment $(b=6.798, S E=.628, p<.000)$, and peer-adolescent attachment $(b=1.456, S E=.620, p=.019)$.

Sibling victimization was related to both perception of social competence $(b=-.118, S E$ $=.044, p=.008)$ and perception of self-worth $(b=-.070, S E=.035, p=.048)$. Sibling victimization was also significantly related to both parent-adolescent attachment $(b=-.182$, $S E=.031, p=.009)$ as well as peer-adolescent attachment $(b=-.090, S E=.039, p=.019)$. Adolescent perception of social competence was related to peer $(b=.300, S E=.050, p<$ .000 ) but not parent-adolescent ( $b=-.028, S E=.049, p=.560)$ attachment. In contrast, adolescent perception of self-worth was related to parent $(b=.291, S E=.043, p<.000)$ but not peer-adolescent $(b=.057, S E=.061, p=.355)$ attachment.

Mediation analyses revealed adolescent perception of social competence to significantly mediate the relationship between sibling victimization and peer-adolescent attachment $\left(b^{*}\right.$ $=-.060, S E=.024, p=.013,95 \%$ CI $[-.122, .002])$. Adolescent perception of self-worth significantly mediated the relationship between sibling victimization and parent-adolescent attachment $\left(b^{*}=-.033, S E=.017, p=.046,95 \%\right.$ CI $\left.[-.077, .010]\right)$. The three-path mediation effects involving parental monitoring sibling victimization social competence and self-worth peer and parent-adolescent attachment were not significant $\left(b^{*}=.006, S E=.001\right.$, $p=.600,95 \%$ CI $[-.007, .019] ; b^{*}=.003, S E=.003, p=.250,95 \%$ CI $\left.[-.004, .011]\right)$.

Results of testing two-group models for gender differences revealed that model fit was significantly worse when paths between parental monitoring and sibling victimization were constrained to be equal between males and females (Wald test $\chi^{2}=7.014, d f=1, p=.008$ ). Further examination showed that parental monitoring was significantly related to sibling victimization for females $\left(b^{*}=-.326, S E=.114, p=.004\right)$ but not for males $\left(b^{*}=.087, S E\right.$ $=.102, p=.393)$. However, there were no gender differences for the associations between sibling victimization and parent and peer attachment (Wald test $\chi^{2}=1.220, d f=2, p=$ .543 ), for the pathway involving sibling victimization self-worth parent attachment (Wald test $\chi^{2}=.908, d f=2, p=.635$ ), and the pathway involving sibling victimization social competence peer attachment (Wald test $\chi^{2}=.2 .543, d f=2, p=.280$ ).

Given that parental monitoring was only significantly related to sibling victimization for girls and not boys, we tested the three path mediation hypotheses (parental monitoring sibling victimization social competence and self-worth peer and parent-adolescent 
attachment) using only girls. The three-path mediation involving parental monitoring sibling victimization self-worth parent-adolescent attachment approached statistical significance $\left(b^{*}\right.$ $=.015, S E=.008, p=.058,95 \%$ CI $[-.005, .035])$. Specific path coefficients for girls are as follows: parental monitoring to sibling victimization $\left(b^{*}=-.326, S E=.114, p=\right.$ .004 ), sibling victimization to self-worth $\left(b^{*}=-.179, S E=.074114, p=.016\right)$, self-worth to parent-adolescent attachment $\left(b^{*}=.232, S E=.062, p<.001\right)$.

The three-path mediation involving parental monitoring sibling victimization social competence peer-adolescent attachment, however, was not significant $\left(b^{*}=.015, S E=.013\right.$, $p=.242,95 \%$ CI $[-.018, .049])$.

\section{Discussion}

The purpose of the current study was to examine parental monitoring as a possible predictor of sibling victimization, and to examine whether sibling victimization is related to parent and peer attachment as mediated by self-perceptions of social competence and self-worth. Additionally, a potential three path mediation from parental monitoring, to parent and peer attachment through sibling abuse and adolescent self-perceptions was examined. The hypothesis that parental monitoring would be related to sibling victimization was supported, but only for girls. The hypothesis that the relationship between sibling victimization and parent and peer attachment would be mediated by adolescent self-perceptions was also partially supported. Specifically, perception of social competence mediated the relationship between sibling victimization and peer-adolescent attachment and perception of self-worth mediated the relationship between sibling victimization and parent-adolescent attachment. Sibling victimization was also directly and negatively related to both parent and peer-adolescent attachment. The hypothesized three path mediations relating parental monitoring and parent-adolescent and peer-adolescent attachment via sibling victimization and adolescent self-perceptions were not significant for the overall group. However, though there is debate about the appropriate discussion of findings that approach significance, we do believe it is worth noting that our findings may hint at evidence that parental monitoring was related to parent-adolescent attachment via sibling victimization and self-worth for girls. We do emphasize that this particular finding requires further research before concrete conclusions can be made.

\section{Parental Monitoring and Sibling Victimization}

Parental monitoring was inversely related to occurrence of sibling victimization, but only for girls. This finding may in part be explained by previous findings that parents are more likely to monitor girls than boys (Svensson, 2003; Tucker, Finkelhor, \& Turner, 2018). In fact, our data suggested that parents of adolescent girls reported higher levels of monitoring than parents of adolescent boys $(t=-2.073, p=.039)$. However, there were no gender differences with respect to adolescents' reports of maternal monitoring $(t=-.502, p=.616)$ or paternal monitoring $(t=-.692, p=.489)$. While it may be that the effect of parental monitoring on sibling victimization is stronger for girls because boys do not receive as much monitoring as girls, our finding also suggests that gender differences in the amount of parental monitoring may depend on the informant. However, it is also possible that parental 
monitoring is a more salient protective factor against sibling victimization for girls than boys because parents monitor different aspects of children's lives between daughters and sons. A direction for future research, then, would be to examine if this is indeed the case and why girls may benefit more from parental monitoring than boys. The present study contributes to literature on sibling victimization by demonstrating that adolescent girls whose parents are aware of and actively monitor their children's activities appear be less likely to experience victimization by a sibling; however, the question remains as to what parental factors may be protective of boys with regard to sibling victimization.

The results or the present study also add to extant literature concerning parental monitoring by showing it to be an important factor related to adolescent self-perceptions. Specifically, both male and female adolescents who experience greater parental monitoring showed higher self-perceptions of social competence and self-worth. Thus, parents who take an active interest in their adolescent's life may be helping their adolescent's confidence in their social competence as well as building their sense of self-worth. Extant research supports the importance of positive self-perceptions of social competence and self-worth. For example, King and colleagues (1993) found both perceptions of social competence and self-worth to be negatively related to depression.

Finally, our results show that higher parental monitoring is related to greater parent and peer-adolescent attachment. The finding that parental monitoring is related to greater parentadolescent attachment is in line with extant literature (e.g., Laird et al., 2003), but this study extends these findings by showing that parents who take an active interest in their adolescent's lives may not only be improving their attachment with their adolescent, but may also be helping their adolescent form good quality relationships with their peers. One of the ways that parental monitoring may contribute to high quality peer relationships is through promoting adolescent self-regulation. Indeed, it has been shown that parental monitoring is positively related to adolescent self-regulation skills (Kim-Spoon, Farley, Holmes, Longo, $\&$ McCullough, 2014). Adolescents with good self-regulation skills also tend to be more socially competent and better liked by their peers (see Farley \& Kim-Spoon, 2014 for a review). Furthermore, prior research demonstrates the importance of good quality parent and peer relationships in that adolescents who have good quality relationships show greater psychological well-being and are at lower risk for reacting to stressful life events in a negative way (see Parker et al., 2006; Longmore, Manning, \& Giordano, 2013 for a review).

\section{Sibling Victimization, Attachment, and Mediation of Self-Perception}

Results show sibling victimization to be related to parent-adolescent attachment both directly and indirectly through self-perception of self-worth. Similarly, sibling victimization is related to peer-adolescent attachment both directly and indirectly through self-perception of social competence. These findings are consistent with previous research on the effects of maltreatment and peer victimization on perceptions of social competence (e.g., Boulton, Smith, \& Cowie, 2010; Grills \& Ollendick, 2002), and our results further establish that sibling victimization may also have similar effects on adolescent perceptions of their own social competence. Such findings address gaps in the literature by elucidating effects of sibling victimization on other relationships as well as highlighting self-perception as a 
mediating process. Extant literature on sibling relationships agrees that sibling interactions are important training tools for future peer interactions (e.g., Herrera \& Dunn, 1997; Volling, 2003; Kramer \& Conger, 2009). It follows that if sibling interactions are a training ground for social interactions and sibling interaction involves victimization experience, then formation of quality peer relationships may be difficult as the child or adolescent has negative previous experience as a reference. The current findings highlight that while sibling relationships can teach positive aspects of peer interaction, abusive sibling interactions may contribute to deficits in the ability to form quality relationships with peers via perceptions of their own social competence. The mediating role of perceived social competence provides potentially useful implications for the development of interventions to help individuals who have experienced victimization by a sibling. For example, the current study did not measure actual social competence, but Stormshak and colleagues (1996) found that high levels of sibling conflict was related to lack of social competence in 1 st and $2^{\text {nd }}$ graders as measured by their teachers. Thus, in future interventions would need to ascertain if adolescents' perceptions of their own social competence is accurate and then interventions can target increasing either adolescents' confidence in their social situations or giving them tools to increase both their actual social competence and their perception of their social competence.

Similarly, our findings showed evidence for self-perception of self-worth as a pathway between sibling victimization and parent-adolescent attachment. These findings are consistent with previous research (e.g., Boulton, Smith, \& Cowie, 2010; Grills \& Ollendick, 2002) that showed peer victimization to negatively affect perception of self-worth and extend these findings by illustrating that sibling victimization is related to perceptions of self-worth in a similar manner to peer victimization. These findings may also help explain Tippett and Wolke's (2015) suggestion that experience of sibling victimization increases the odds of peer victimization. For example, research shows that adolescent self-perceptions are reciprocally related to peer victimization (Boulton, Smith, \& Cowie, 2010), therefore a direction for future research might be to examine whether sibling victimization increases risk for peer victimization via adolescent self-perceptions.

Our finding of the positive association between abusive sibling relationship and poor quality parent-adolescent relationship demonstrates how family subsystems (e.g., parent-child relationship, sibling relationship) may be interrelated. Furthermore, the current findings suggest that the link between sibling victimization and poor quality parent-adolescent relationship can be, in part, due to the detrimental effect of sibling victimization on adolescent perception of self-worth. Extant research on perceptions of self-worth and attachment suggests that having good relationships is related to high levels of self-worth and self-esteem (e.g. Kenny, \& Sirin, 2011). The three path mediation parental monitoring sibling victimization self-worth parent-adolescent attachment finding in the current study provides evidence that the association of self-worth and parent-child attachment may be reciprocal. Parents who engage in positive parenting practices such as parental monitoring may help develop their child's self-worth (perhaps via prevention of detrimental situations such as sibling victimization) which in turn may contribute to strengthened parent-child relationships. However, it should be noted that this finding was only approaching significance and only for girls, and therefore should be interpreted with caution and further research. A more detailed examination of these findings is continued on the next page. 
No gender differences were found among the mediated relationship, parental monitoring sibling victimization social competence and self-worth parent-adolescent and peer attachment, which was surprising given previous research. For example, Grills and Ollendick (2002) noted that the associations between peer victimization and perceptions of self-worth were stronger for girls than for boys. The authors suggested that because girls are more likely to have greater emotional investment in relationships they may be more likely to internalize negative feedback. Similarly, Kim and colleagues (1999) suggested that girls may be more reactive to hostility/negativity within the sibling relationship than are boys. Girls, then, may be more likely than boys to internalize negative feedback from siblings than boys. Thus, extant research suggests that sibling victimization may put girls at greater risk than boys for negative outcomes. The current study found no such tendency. The discrepancy between the findings of these prior studies and the current study's findings may be in part due to the difference in the outcomes. It is possible that gender differences exist particularly for the associations between abusive relationships and adjustment problems, such as internalizing and externalizing symptomatology. Future research on sibling victimization should continue to explore possible gender differences, specifically whether boys exhibit greater resilience in the face of sibling victimization.

\section{Parental Monitoring, Attachment, and Mediation of Sibling Victimization and Self-Worth}

We begin this section with due caution in interpreting near significant results, however, we do believe the results merit discussion as they may inform important directions for future research. Results may provide evidence that, for girls, the relationship between parental monitoring and parent-adolescent attachment is mediated via sibling victimization and perception of self-worth. Specifically, lower parental monitoring was related to occurrence of sibling victimization, which was related to lower perception of self-worth, which in turn was related to lower parent-adolescent attachment. This finding provides preliminary evidence to literature on parental monitoring by suggesting pathways through which parental monitoring may be related to female adolescents having quality relationships with their parents. It appears that the gender differences in this relationship are driven by parental monitoring being related to sibling victimization only for girls. Such findings highlight that further research is warranted regarding gender differences in protective and risk factors for sibling victimization. Furthermore, although it is possible that the lack of true significance for these results $(p=.058)$ may be due to low rates of sibling victimization among our sample, we strongly suggest that further research needs to be conducted to verify the results before strong conclusions can be made about the pathways through which parental monitoring may be related to adolescent-parent relationships.

\section{Implications for Interventions}

So far we have noted that the results of the current study may provide helpful information to the development of interventions such as parental monitoring as a protective factor against sibling victimization for girls. In cases where sibling victimization is not prevented, and targeting perceptions of social competence among adolescents who have experienced sibling victimization may be especially important in helping adolescents develop positive peer attachment. Similarly, perceptions of self-worth seem to be specifically related to positive 
parent attachment, therefore interventions may focus on improving parent-adolescent relationships through helping parents build their children's perception of self-worth.

Perhaps one of the most major implications of current study for future interventions is to seriously consider that parenting interventions may be necessarily different for girls and boys. Kramer (2010) makes a number of research based suggestions for parenting behaviors that can foster positive sibling relationships however, further research may be necessary to determine if, like with parental monitoring, other protective factors against sibling abuse may be differentially efficacious for girls and boys.

\section{Limitations and Conclusion}

There are some methodological strengths of this study as well as well as some limitations that suggest directions for future research. A strength of the current study is that we used a latent variable of parental monitoring based on data from multiple informants. Adolescents reported on their mothers' and fathers' monitoring behavior and the primary caregiver reported on their own monitoring behavior. Another strength of the study is that we were able to look at the effects of sibling victimization over and above the effects of victimization by other individuals. Despite these strengths, some methodological limitations should be noted. First, our findings were based on cross-sectional, correlational data and do not establish causality in relations among the study variables. The mediated effects found in this study warrant further replications using longitudinal, multiple-wave data. A second limitation is that all our data are based on self-report. In addition, except for parental monitoring, sibling victimization, self-perception and attachment variances relied on single informant using adolescents' self-report. Future research would benefit from the use of multiple methods/informants of data collection to reduce possible biases due to shared method variances.

Another potential limitation of the study is that no information on sibling age, birth order, or gender was collected. Thus, it is unknown how such variables may or may not influence the findings of the current study. Extant research does show sibling victimization tends to be higher among brother-brother pairs, and for siblings of similar age (Tucker et al., 2013). Thus, sibling age and gender should be an important consideration for any future research.

In conclusion, the current study contributes to literature on sibling victimization by illuminating familial and social relationship correlates of sibling victimization including parental monitoring and adolescent attachment with parents and peers. For both girls and boys, sibling victimization was related to poor parent- and peer-adolescent attachment and these associations were explained by poor adolescent self-perceptions of social competence and self-worth predicted by sibling victimization. Thus our findings present preliminary evidence for pathways that involve adolescent self-perceptions through which sibling victimization may predict the ability to form quality relationships over and above the effects of other types of victimization. Results imply that parental monitoring may be important in the prevention of sibling victimization, at least for girls, and adolescent self-perceptions may be an important point of intervention for attenuating the detrimental effects of sibling victimization. 


\section{Acknowledgments}

This research was supported by grants awarded to Jungmeen Kim-Spoon, Ph. D. from the National Institute of Child Health and Human Development (HD057386) and the National Institute of Drug Abuse (DA036017). We thank Laurel Marburg, Eirini Papafratzeskakou, Diana Riser, Gregory Longo, and Julee Farley for their help with data collection. We are grateful to our study participants.

\section{References}

Armsden GC, \& Greenberg MT (1987). The inventory of parent and peer attachment: Individual differences and their relationship to psychological well-being in adolescence. Journal of Youth and Adolescence, 16, 427-454. doi; 10.1007/BF02202939 [PubMed: 24277469]

Bank L, Burraston B, \& Snyder J (2004). Sibling conflict and ineffective parenting as predictors of adolescent boys' antisocial behavior and peer difficulties: Additive and interactional effects. Journal of Research on Adolescence, 14, 99-125. doi: 10.1111/j.1532-7795.2004.01401005.x

Boulton MJ, Smith PK, \& Cowie H (2010). Short-term longitudinal relationships between children's peer victimization/bullying experiences and self-perceptions: Evidence for reciprocity. School Psychology International, 31, 296-311. doi: 10.1177/0143034310362329

East PL (2009). Adolescents' relationships with siblings. In Lerner RM \& Steiberng L (Eds.), Handbook of adolescent psychology (pp. 43-73). Hoboken, NJ: Wiley.

East PL, \& Khoo ST (2005). Longitudinal pathways linking family factors and sibling relationship quality to adolescent substance use and sexual risk behaviors. Journal of Family Psychology, 19, 571-580. doi: 10.1037/0893-3200.19.4.571 [PubMed: 16402872]

Farley JP, \& Kim-Spoon J (2014). The development of adolescent self-regulation: The role of parent, peer, friend, and romantic relationships. Journal of Adolescence, 37, 433-440. doi: 10.1016/ j.adolescence.2014.03.009 [PubMed: 24793391]

Finkelhor D, Hamby SL, Ormrod R, \& Turner H (2005). The Juvenile Victimization Questionnaire: Reliability, validity, and national norms. Child Abuse and Neglect, 29, 383-412. doi: 10.1016/ j.chiabu.2004.11.001 [PubMed: 15917079]

Furman W, \& Giberson RS (1995). Identifying the links between parents and their children's sibling relationships. In Shulman S (Ed.), Human development, Vol. 7. Close relationships and socioemotional development. (pp. 95-108). Westport, CT, US: Ablex Publishing.

Garcia MM, Shaw DS, Winslow EB, \& Yaggi KE (2000). Destructive sibling conflict and the development of conduct problems in young boys. Developmental Psychology, 36, 44-53. doi: 10.1037//0012-1649.36.1.44 [PubMed: 10645743]

Grills AE, \& Ollendick TH (2002). Peer victimization, global self-worth and anxiety in middle school children. Journal of Clinical Child and Adolescent Psychology, 31, 59-68 doi: 10.1207/153744202753441675 [PubMed: 11845651]

Harter S (1979). Manual: Perceived Competence Scale for Children. University of Denver.

Herrera C, \& Dunn J (1997). Early experiences with family conflict: Implications for arguments with a close friend. Developmental Psychology, 33, 869-881. doi: 10.1037//0012-1649.33.5.869 [PubMed: 9300220]

Hetherington EM, \& Clingempeel WG (1992). Coping with marital transitions: A family systems perspective. Monographs of the Society for Research in Child Development, 57, 1-14. doi: $10.2307 / 1166050$

Hoffman KL \& Edwards JN (2004). An integrated theoretical model of sibling violence and abuse. Journal of Family Violence, 19, 185-200. doi: 10.1023/B:JOFV.0000028078.71745.a2

Kenny ME, \& Sirin SR (2011). Parental attachment, self-worth, and depressive symptoms among emerging adults. Journal of Counseling and Development, 84, 61-71. doi: 10.1002/ j.1556-6678.2006.tb00380.x

Kim J, \& Cicchetti D (2004). A longitudinal study of child maltreatment, mother-child relationship quality and maladjustment: The role of self-esteem and social competence. Journal of Abnormal Child Psychology, 32, 341-354. doi: 10.1111/j.1939-0025.2012.01154.x [PubMed: 15305541] 
Kim J, Hetherington EM, \& Reiss D (1999). Associations among family relationships, antisocial peers, and adolescents' externalizing behaviors: Gender and family type difference. Child Development, 70, 1209-1230. doi: 10.1111/1467-8624.00088 [PubMed: 10546341]

Kim-Spoon J, Farley JP, Holmes CJ, Longo GS, \& McCullough ME (2014). Processes linking parents' and adolescents' religiousness and adolescent substance use: Monitoring behaviors and self-regulation. Journal of Youth and Adolescence, 43, 745-756. doi:10.1007/s10964-013-9998-1 [PubMed: 23975353]

King CA, Naylor MW, Segal HG, Evans T, \& Shain BN (1993). Global self-worth, specific selfperceptions of competence and depression in adolescents. Journal of the American Academy of Child and Adolescent Psychiatry, 32, 745-752. doi: 10.1097/00004583-199307000-00007 [PubMed: 8340294]

Kiselica MS, \& Morrill-Richards M (2007). Sibling maltreatment: The forgotten abuse. Journal of Counseling \& Development, 85, 148-160. doi: 10.1002/j.1556-6678.2007.tb00457.x

Kramer L (2010). The essential ingredients of successful sibling relationships: An emerging framework for advancing theory and practice. Child Development Perspectives, 4, 80-86. doi: 10.1111/j.1750-8606.2010.00122.x

Kramer L, \& Conger KJ (2009). What we learn from our sisters and brothers: For better or for worse. New Directions for Child and Adolescent Development, 2009(126), 1-12. doi: 10.1002/cd.253

Kramer L, Perozynski LA, \& Chung T (1999). Parental responses to sibling conflict: The effects of development and parent gender. Child Development, 70, 1401-1414.doi: 10.1111/1467-8624.00102 [PubMed: 10621963]

Krienert JL, \& Walsh JA (2011). My brother's keeper: A contemporary examination of reported sibling violence using national level data, 2000-2005. Journal of Family Violence, 26, 331-342. doi: 10.1007/s10896-011-9367-3

Kline RB (1998). Principles and practice of structural equation modeling. New York: Guilford.

Laird RD, Pettit GS, Dodge KA, \& Bates JE (2003). Change in parents' monitoring knowledge: Links with parenting relationship quality, adolescent beliefs, and antisocial behavior. Social Development, 12, 401-419. doi: 10.1111/1467-9507.00240 [PubMed: 20209033]

Longmore MA, Manning WD, \& Giordano PC (2013). Parent-child relationships in adolescence. In Fine MA, \& Fincham FD (Eds.), Handbook of family theories: A content-based approach (pp. 28-50). New York: Routledge.

Milevsky A, \& Levitt MJ (2005). Sibling support in early adolescence: Buffering and compensation across relationships. European Journal of Developmental Psychology, 2, 299-320. doi: $10.1080 / 17405620544000048$

Murray SL, Holmes JG, \& Griffin DW, (2000). Self-esteem and the quest for felt security: How perceived regard regulates attachment processes. Journal of Personality and Social Psychology, 78, 478-498. doi: 10.1037//0022-3514.78.3.478 [PubMed: 10743875]

Morrill-Richards M, \& Leierer SJ (2010). The relationship between sibling maltreatment and college students' sense of well-being. Journal of College Counseling, 13, 17-30. doi: 10.1002/ j.2161-1882.2010.tb00045.x

Muthén LK, \& Muthén B (2010). Mplus user's guide [Computer software and manual], (6th Ed.). Los Angeles, CA: Muthén \& Muthén.

Parker JG, Rubin KH, Erath SA, Wojslawowicz JC, \& Buskirk AA (2006). Peer relationships, child development, and adjustment: A developmental psychopathology perspective. In Cicchetti D \& Cohen DJ (Eds.), Developmental psychopathology: Theory and method, Volume 1 (419-493).

Raja SN, McGee R, \& Stanton WR (1992). Perceived attachments to parents and peers and psychological well-being in adolescence. Journal of Youth and Adolescence, 21, 471-485. doi: 10.1007/BF01537898 [PubMed: 24263975]

Simonelli CJ, Mullis T, Elliott AN, \& Pierce TW (2002). Abuse by siblings and subsequent experiences of violence within the dating relationship. Journal of Interpersonal Violence, 17, 103 121. doi: $10.1177 / 0886260502017002001$

Stocker CM, \& McHale SM (1992). The nature and family correlates of preadolescents' perceptions of their sibling relationships. Journal of Social and Personal Relationships, 9, 19-195. doi: $10.1177 / 0265407592092002$ 
Stormshak EA, Bellanti CJ, Bierman KL, and Condct Problems Prevention Research Group. (1996). The quality of sibling relationships and the development of social competence and behavioral control in aggressive children. Developmental Psychology, 32, 79-89. doi: 10.1037/0012-1649.32.1.79

Svensson R (2003). Gender differences in adolescent drug use: The impact of parental monitoring. Youth Society, 34, 300-329. doi: 10.1177/0044118X02250095

Taylor AB, MacKinnon DP, \& Tein J (2008). Tests of the three-path mediated effect. Organizational Research Methods, 11, 241-269. doi: 10.1177/1094428107300344

Tippett N, \& Wolke D (2015). Aggression between siblings: Associations with the home environment and peer bullying. Aggressive Behavior, 41, 14-24. doi: 10.1002/ab.21557 [PubMed: 25187483]

Tucker CJ, Finkelhor D, Shattuck AM, \& Turner H,(2013). Prevalence and correlates of sibling victimization types. Child Abuse and Neglect, 37, 213-223. doi: 10.1016/j.chiabu.2013.01.006 [PubMed: 23428164]

Tucker CJ, Finkelhor D, Turner H, \& Shattuck AM (2013). Association of sibling aggression with child and adolescent mental health. Pediatrics, 132, 79-84. doi: 10.1542/peds.2012-3801 [PubMed: 23776124]

Tucker CJ, Finkelhor D, Turner H, \& Shattuck AM (2014). Family dynamics and young children's sibling victimization. Journal of Family Psychology, 28, 625- 633. doi: 10.1037/fam0000016 [PubMed: 25111955]

Tucker CJ, Finkelhor D, \& Turner H (2018). Family adversity's role in the onset and termination of childhood sibling victimization. Psychology of Violence, 8, 10-18. doi: 10.1037/vio0000087

Updegraff KA, Thayer SMWhiteman SD, Denning DJ, \& McHale SM (2005). Relational aggression in adolescents' sibling relationships: Links to sibling and parent-adolescent relationship quality. Family Relations, 54, 373-385. doi: 10.1111/j.1741-3729.2005.00324.x

Volling BL (2003). Sibling Relationships. In Bornstein MH, Davidson L, Keyes CLM, \& Moore KA (Eds.), Well-Being: Positive Development Across the Life Course. Crosscurrents in Contemporary Psychology (pp. 205-220). Mahwah, NJ: Lawrence Erlbaum Associates.

Wiehe VR, \& Herring T (1991). Perilous rivalry: When siblings become abusive. Lexington, MA: Lexington Books.

Wolke D, Tippett N, \& Dantchev S (2015). Bullying in the family: Sibling bullying. The Lancet Psychiatry, 2, 917-929. doi: 10.1016/S2215-0366(15)00262-X [PubMed: 26462226]

Yabko BA, Hokoda A, \& Ulloa EC, (2008). Depression as a mediator between family factors and peer-bullying victimization in Latino adolescents. Violence and victims, 23, 727-742. doi:10.1891/0886-6708.23.6.727 [PubMed: 19069564]

J Early Adolesc. Author manuscript; available in PMC 2021 September 15. 


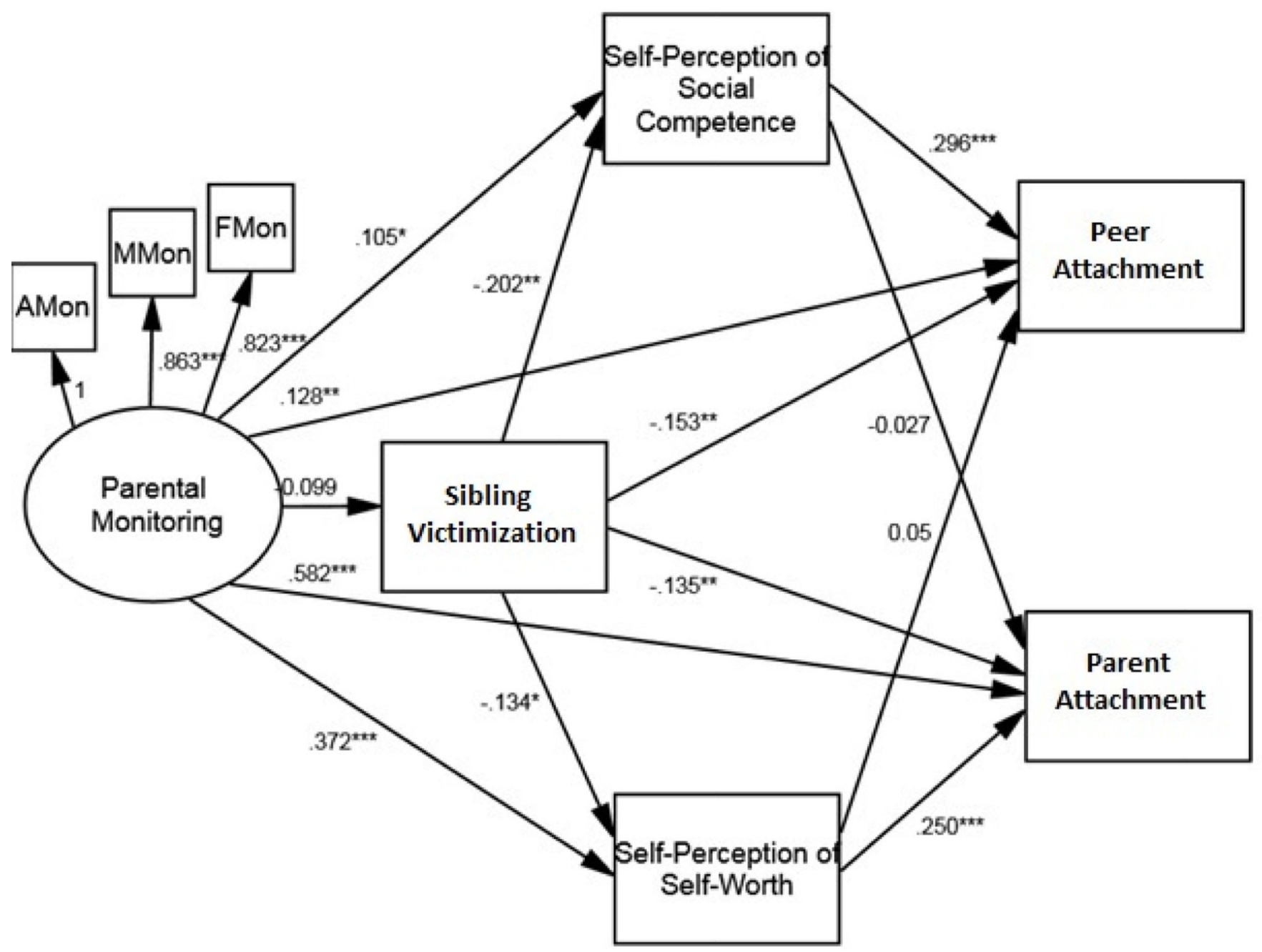

Figure 1.

Summarized model fitting results of the associations among parental monitoring, sibling victimization, self-perceptions, and parent and peer attachment.

Notes. Standardized parameter estimates are presented. For clarity of presentation, the following correlation coefficients are not shown: social competence $\leftrightarrow$ self-worth, $r$ $=.52^{* * *}$; parent-adolescent attachment $\leftrightarrow$ peer-adolescent attachment, $r=.05$; sibling victimization $\leftrightarrow$ other abuse, $r=-.28^{* * *}$. The following coefficients related to age, income, and other abuse covariates are not shown: age $\rightarrow$ parent attachment, $b^{*}=-.01$; income $\rightarrow$ peer attachment, $b^{*}=.07$; other abuse $\rightarrow$ social competence, $b^{*}=-.21^{* *}$; other abuse $\rightarrow$ self-worth, $b^{*}=-.16^{* *}$; other abuse $\rightarrow$ parent attachment, $b^{*}=-.05$; other abuse $\rightarrow$ peer attachment, $b^{*}=-.17 * *$.

$* p<.05 ; * * p \leq .01 * * * p<.001$ 

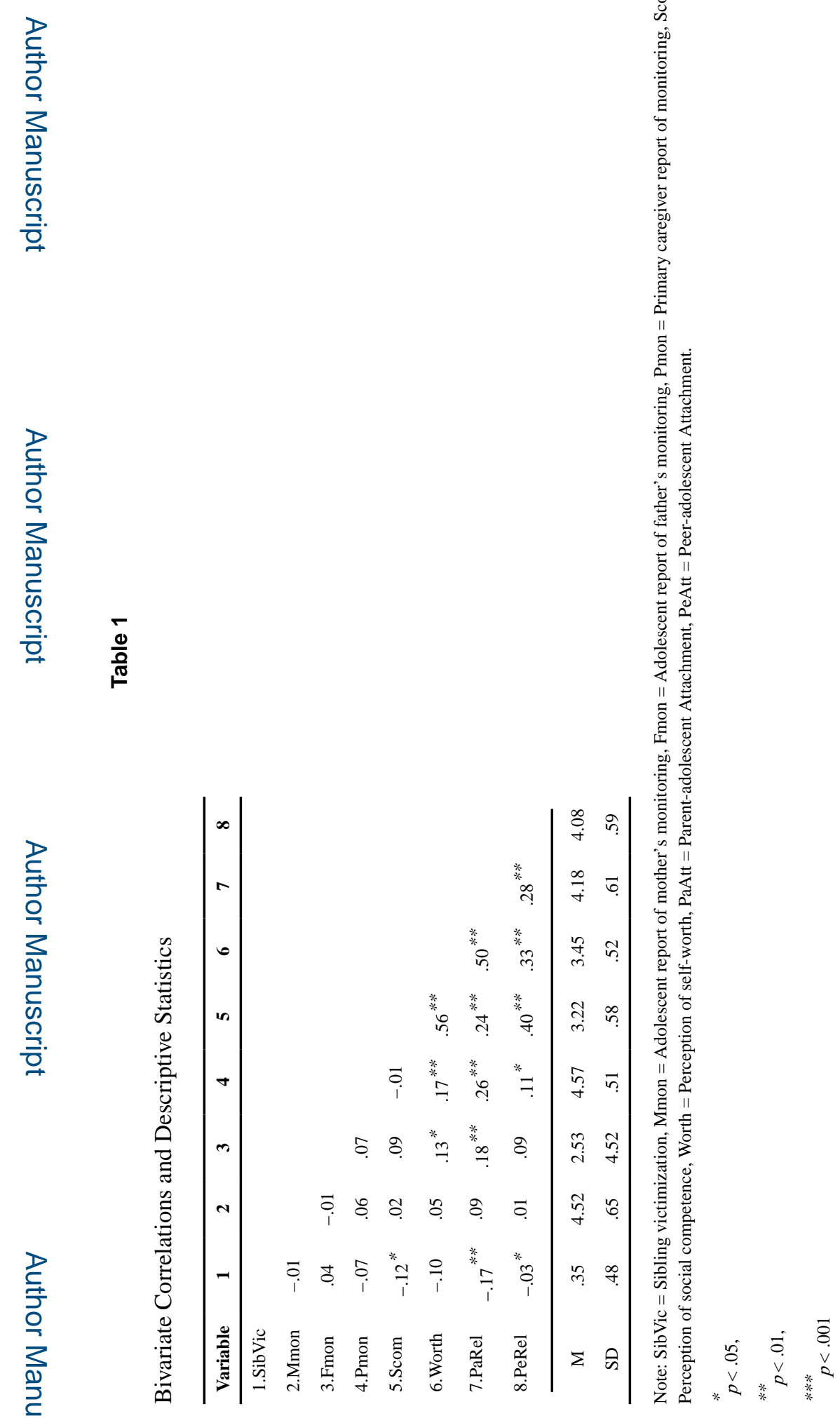